\title{
Editorial Policy on Co-authorship of Articles from Low- and Middle-Income Countries
}

\author{
Adam L. Kushner • Patrick Kyamanywa - Charles A. Adisa • \\ Pascience Kibatala $\cdot$ Nyengo Mkandawire $\cdot$ Peter Coleman • \\ Thaim B. Kamara $\cdot$ Charles N. Mock · John G. Hunter
}

Published online: 8 September 2011

(C) Société Internationale de Chirurgie 2011

Global health and the support of surgical research, education, and clinical care in low- and middle-income countries (LMICs) are primary missions of the World Journal of Surgery. As surgery is increasingly recognized as a costeffective and necessary component of public health [1] more researchers are directing their attention to the issue of surgical capacity, innovations, or conditions in LMICs. With academic and professional collaborations often transcending national borders, it is important to clearly address the issues of co-authorship and sharing the benefits of research.

We feel it is inappropriate to publish scientific papers regarding conditions, capacity or innovations in LMICs without involving local scientists. In addition to potentially violating the local population's trust, policy makers and

\footnotetext{
A. L. Kushner $(\square)$

Surgeons OverSeas (SOS), Society of International Humanitarian Surgeons, 225 East 6th Street, New York, NY 10003, USA

e-mail: adamkushner@yahoo.com
}

\section{A. L. Kushner}

Department of Surgery, Columbia University, 630 West 168th Street, New York,

NY 10032, USA

P. Kyamanywa

Department of Surgery, Faculty of Medicine, National University of Rwanda, P.O. Box 56, Butare, Rwanda

C. A. Adisa

Department of Surgery, Abia State University, PMB 2000 Uturu, Nigeria

\section{P. Kibatala}

Ministry of Health, Samora Avenue,

P.O.B. 9083, Dar es Salaam, Tanzania government authorities in LMICs are more likely to accept and act on the results of research done in their countries if they know that local experts have been involved.

To address these concerns, the World Journal of Surgery has decided to introduce a new policy regarding original research received using primary data from LMICs. The journal will now require that all such manuscripts include at least one local co-author. A local co-author is defined as a national of that country who is living and working in the home country.

The editors understand that there may be extenuating circumstances in which this requirement cannot be met. In such cases, a cover letter should explain why a local co-author is not included.
N. Mkandawire

Department of Surgery, College of Medicine,

University of Malawi, Blantyre, Malawi

P. Coleman

Department of Surgery, A. M. Dogliotti College of Medicine,

University of Liberia, Monrovia, Liberia

\section{T. B. Kamara}

Department of Surgery, Connaught Hospital, Freetown,

Sierra Leone

C. N. Mock

Department of Surgery, University of Washington,

1959 NE Pacific Street, P.O. Box 356410 ,

Seattle, WA 98195, USA

J. G. Hunter

Department of Surgery, Oregon Health Sciences University,

3181 SW Sam Jackson Park Road, Portland,

OR 97239-3098, USA 


\section{References}

1. Bae JY, Groen RS, Kushner AL (2011) Surgery as a public health intervention: common misconceptions versus the truth. Bull World Health Organ 89:395 